\title{
Assessment of Ecosystem Service Value and Its Differences in the Yellow River Basin and Yangtze River Basin
}

\author{
Chunsheng $\mathrm{Wu}^{1,2}$, Guoxia $\mathrm{Ma}^{2}$, Weishan Yang ${ }^{2}$, Ying Zhou ${ }^{2}$, Fei Peng ${ }^{2}$, Jinnan Wang ${ }^{2}$ and Fang $\mathrm{Yu}^{2, *}$ \\ 1 Lhasa Plateau Ecosystem Research Station, Key Laboratory of Ecosystem Network Observation \\ and Modeling, Institute of Geographic Sciences and Natural Resources Research, Chinese Academy \\ of Sciences, Beijing 100101, China; wucs@igsnrr.ac.cn \\ 2 Center for Eco-Environmental Accounting, Chinese Academy of Environmental Planning, \\ Beijing 100012, China; magx@caep.org.cn (G.M.); yangws@caep.org.cn (W.Y.); zhouying@caep.org.cn (Y.Z.); \\ pengfei@caep.org.cn (F.P.); wangjn@caep.org.cn (J.W.) \\ * Correspondence: yufang@caep.org.cn
}

Citation: Wu, C.; Ma, G.; Yang, W.; Zhou, Y.; Peng, F.; Wang, J.; Yu, F. Assessment of Ecosystem Service Value and Its Differences in the Yellow River Basin and Yangtze River Basin. Sustainability 2021, 13, 3822. https://doi.org/10.3390/su13073822

Academic Editor: Lucio Di Matteo

Received: 17 February 2021

Accepted: 24 March 2021

Published: 31 March 2021

Publisher's Note: MDPI stays neutral with regard to jurisdictional claims in published maps and institutional affiliations.

Copyright: () 2021 by the authors. Licensee MDPI, Basel, Switzerland. This article is an open access article distributed under the terms and conditions of the Creative Commons Attribution (CC BY) license (https:// creativecommons.org/licenses/by/ $4.0 /)$.

\begin{abstract}
The Yellow River Basin and the Yangtze River Basin are the two most important watersheds in China, which consist of several key ecological function areas and are crucial in terms of economic contributions. The evaluation of the ecosystem service value and the quantitative acquisition of the regional ecological quality status are necessary for supporting the ecological protection and highquality development of the two basins. By considering basic data and adopting different ecological function models, this study was carried out to evaluate the value of ecosystem services in the Yellow River Basin and the Yangtze River Basin from 2015 to 2018 in terms of provisioning services, regulating services, and cultural services. Additionally, analysis was conducted in combination with economic indicators. The results showed that there were great differences in the ecosystem patterns between the Yellow River Basin, where grassland accounted for $45 \%$ of land use, and the Yangtze River Basin, where forest accounted for $39 \%$ of land use. The values of the ecosystem services of the two basins had similar spatial distributions, with higher values upstream (west) followed by downstream (east) and lower values in the middle (central China). The total annual ecosystem value of the Yangtze River Basin was more than three times that of the Yellow River Basin. In addition, the ecosystem services value of most counties in both basins was higher than their GDP, and there was a positive trend of transforming ecological benefits into economic benefits in the Yangtze River Basin. This research provides a methodology for evaluating ecosystem valuation. The results are helpful for formulating and implementing eco-compensation and payments for ecosystem service policies among different regions in the basins, and the results lay a foundation for the spatial planning and high-quality development paths of key basin areas in China.
\end{abstract}

Keywords: ecosystem services value; ecological models; Yellow River Basin; Yangtze River Basin; high-quality development

\section{Introduction}

The ecosystem is a dynamic, complicated, and interactive functional unit composed of flora, fauna, microbial flora, and abiotic environments, from which human beings acquire various goods and services either directly or indirectly. Ecosystem service valuation is the quantification of these services in monetary form [1,2]. With continual social and economic development, people are gradually demanding fewer materials but need more from the surrounding environment, such as spiritual and cultural values, which elicits an acute awareness of the capacity of the surrounding ecosystem to provide these benefits [3], thereby making it necessary to express ecosystem services quantitatively. Quantification from a purely ecological point of view is difficult for the public to understand, but by drawing upon the expression for gross national economic product (GDP) and using market 
or other model methods to value ecosystem services, it is easy to popularize and facilitate comparative analysis with economic indicators [4].

The evaluation of ecosystem service value requires a reasonable definition of the types and structures of ecosystem services. Costanza, who established and applied this theory and method as a pioneer, defined 17 types of global ecosystem services in 1997, including product provisioning, air, soil, hydrologic regulation, biological conservation, and cultural services and completed the valuation of each service based on the public's willingness to pay (WTP) [5]. Since the research of Costanza [6] and Daily [7], the Millennium Ecosystem Assessment launched by the UN in 2001 and Experimental Ecosystem Accounting (EEA) (an account of the System of Integrated Environmental and Economic Accounting (SEEA)) released in 2012 divided global ecosystem services into three service systems (provisioning services, regulating services, and cultural services) for valuation with 19 indicators [8]. Most of the following studies focused on indicator design from various perspectives, inspired by this system [9-16]. The methods selected by scholars have also been continuously evolving [17-19], ranging from subjective and objective evaluation methods, including the WTP method and market value method $[3,20]$, to material conversion-based evaluation methods, including the energy conversion method and equivalent factor method [21,22]. The introduction of spatial methods such as GIS and remote sensing [23] has further mitigated the limitations of overgeneralization in the evaluation process, while the results are elaborated in greater detail with the increasing spatial resolution of basic data [24]. Moreover, researchers tend to adopt different methods in their research, but no method is immune from disadvantages [3]. For example, in the equivalent value method, the variation in the standard equivalence factor in spatial and temporal scales is not considered in most studies or roughly rectified with various methods $[3,25,26]$. The energy value conversion rate adopted in different studies is very different when using the energy value conversion method [27], making it not useful for comparing the evaluation results from different studies. Therefore, research still needs to continue to explore and improve the evaluation of the ecosystem service value [28], especially when it is necessary to establish a method system that is acceptable to the general public.

As the two most important river basins in China, the Yellow River Basin and Yangtze River Basin account for a considerable share of the land area and economic volume of the country, and their importance has been highlighted with the Yangtze River Economic Belt and with the strategy of high-quality development of the Yellow River Basin taking shape in recent years. Moreover, the two river basins feature high biodiversity and key ecological functional zones and are important for China's ecological security [29-31]. Many studies and reports have been published on the comparison of economic development levels and evolving trends [32-35] between the two basins. However, there has not been much research on the accounting of the value of ecosystem services in the two major river basins.

This study uses the Yellow River and Yangtze River basins as the objects of research. The study first comprehensively evaluates the ecosystem service values of the two basins, then compares and analyzes the trends in time and space and, finally, combines the assessment results with the regional GDP to explore the developmental relationship between the socioeconomic and the eco-environment, analyzing the current status and prospects of the regional green development and giving suggestions for improving existing problems. This study provides technical and methodological support for the evaluation of regional ecosystem service value, and its results provide data for the green development of various administrative units in the river basins and offer input for decision-making in regional economic and eco-environmental planning and policymaking. We also hope that the method in this article can be accepted by other researchers to facilitate the comparison of related research in different regions. 


\section{Materials and Methods}

\subsection{Study Area}

Combining the degree of sophistication of this research and the degree of integration with socioeconomic data, this research selected all county-level administrative divisions within or partly within the natural scope of the Yellow River Basin and the Yangtze River Basin as the study area (Figure 1). The statistical data show that the study area included 1224 counties within $24-109^{\circ} \mathrm{N}$ and $89-122^{\circ} \mathrm{E}$, among which 365 counties are in the Yellow River Basin, located across the Shandong, Henan, Shanxi, Shaanxi, Gansu, Qinghai, and Sichuan provinces, as well as Inner Mongolia and the Ningxia Autonomous Region, with a total area of approximately 1.1 million $\mathrm{km}^{2}$. There are 859 counties in the Yangtze River Basin, located across the Shanghai, Chongqing, Jiangsu, Zhejiang, Anhui, Jiangxi, Hubei, Hunan, Henan, Shaanxi, Guizhou, Sichuan, Yunnan, and Qinghai provinces, as well as Guangxi and the Tibet Autonomous Region, with a total area of approximately 1.9 million $\mathrm{km}^{2}$. The total area of the two river basins accounts for approximately $31.1 \%$ of the overall land area of China.

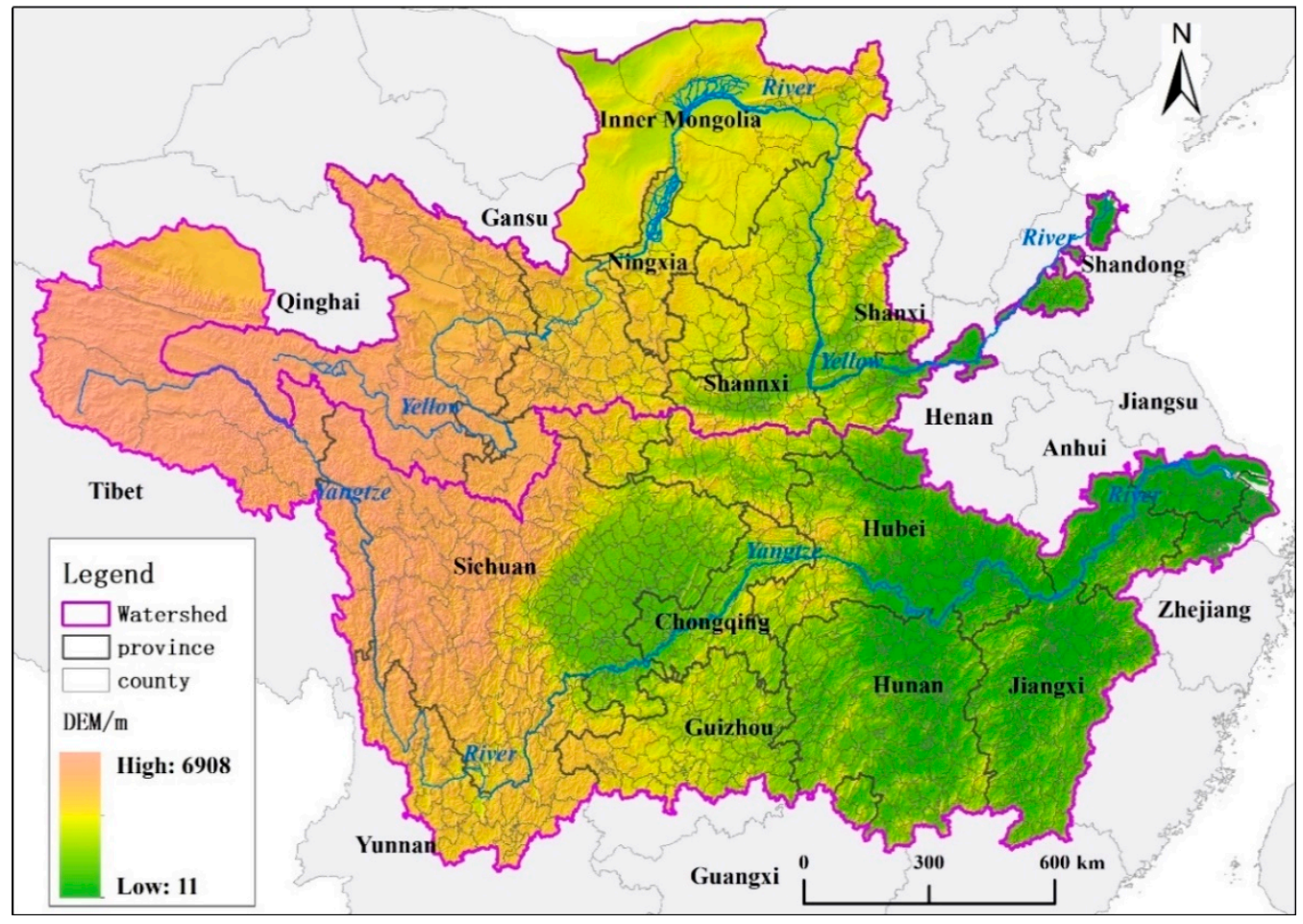

Figure 1. Scope and topographic conditions of the study area.

The topography of the two basins has a similar pattern; they both decrease in elevation from west to east, with their western part located on the rim of the Qinghai-Tibet Plateau. The northern part of the Yellow River Basin is located on the Inner Mongolia Plateau, and its middle part is located on the Loess Plateau, whereas the Shandong and Henan provinces in the eastern part of the basin consist of plains with lower elevations. With a temperate monsoonal climate and temperate continental climate as the main climate types, the Yellow River Basin features significant variation in annual precipitation, with the maximum rainfall exceeding $1000 \mathrm{~mm}$ and the minimum rainfall being lower than $100 \mathrm{~mm}$. The western part of the Yangtze River Basin is located on the eastern rim of the Qinghai-Tibet Plateau with a maximum altitude of approximately $6908 \mathrm{~m}$, and the southwestern region and the surrounding area of the Sichuan Basin are also higher in elevation. On the other hand, most of its central and eastern parts consist of lower hilly areas or plains. The climate types of the Yangtze River Basin are mainly a subtropical monsoonal climate and alpine climate, where the precipitation is higher than that in the 
Yellow River Basin, with the maximum rainfall exceeding $2000 \mathrm{~mm}$ and the minimum being lower than $400 \mathrm{~mm}$.

As the main population centers, the socioeconomic development of the Yellow River and Yangtze River basins has maintained a high level in the country. From 2015 to 2018, the total GDP of the two basins accounted for approximately $44 \%$ of the national total, but each region has specific differences in their natural endowments and development policies. With the gradual advancement of reform and the opening up of the economy, their gap in economic development has gradually widened according to the China Statistical Yearbook. The consumption of natural resources by social and economic development, as well as changes in the patterns of the ecosystems, affect the service functions of the ecosystem, which in turn hinders further social and economic development.

\subsection{Indicators and Methods}

This study established a framework of ecosystem service valuation for the two basins based on the results of previous researchers and considering the data availability and method feasibility, where indicators were classified into three categories-provisioning services, regulating services, and cultural services (Table 1) — to evaluate the physical and monetary quantities.

Table 1. Indicators of the ecosystem service valuation of the two basins.

\begin{tabular}{cc}
\hline Services & Evaluation Indicator \\
\hline Provisioning services & Agriculture, forestry, fishery, animal products, bioenergy \\
\hline & Water conservation \\
Regulating services & Soil conservation \\
& Sand fixing \\
& Flood regulation \\
& Carbon fixation and oxygen release \\
Cultural services & Climate regulation \\
\hline
\end{tabular}

\subsubsection{Provisioning Services}

People obtain products from the ecosystem that can be traded in the marketplace to meet the material needs of human life, production, and development. These products include agricultural, forestry, animal husbandry, fishery, and other products, as well as ecological energy. The market value method was used to evaluate the value of the material products and services from the ecosystem:

$$
V_{m}=\sum_{i=1}^{n} E_{i} \times P_{i}
$$

where $V_{m}$ is the value of the material product of the ecosystem (cny/a), $E_{i}$ is the output of the $i$ th ecosystem product, and $P_{i}$ is the price of the $i$ th ecosystem product, which is determined according to the market price.

\subsubsection{Water Conservation}

The water balance equation was chosen to calculate the water conservation amount [36,37]; the shadow engineering method was used to obtain the value; and the engineering cost and maintenance cost of the reservoir were used as the price parameters:

$$
\begin{gathered}
Q_{w r}=\sum_{i=1}^{n} A_{i} \times\left(P_{i}-R_{i}-E T_{i}\right) \times 10^{-3} \\
V_{w r}=Q_{w r} \times C_{w e}
\end{gathered}
$$


where $Q_{w r}$ is the water conservation amount ( $\left.\mathrm{m}^{3} / \mathrm{a}\right), P_{i}$ is the precipitation (mm/a), $R_{i}$ is the surface runoff (mm/a), $E T_{i}$ is the evapotranspiration (mm/a), $A_{i}$ is the area of the type $i$ ecosystem $\left(\mathrm{m}^{2}\right), V_{w r}$ is the value of water conservation $(\mathrm{CNY} / \mathrm{a})$, and $C_{w e}$ is the engineering cost and maintenance cost of the reservoir $\left(\mathrm{CNY} / \mathrm{m}^{3}\right)$, which can be obtained from the project cost of the water conservancy department.

\subsubsection{Soil Conservation}

Soil conservation uses the amount of soil conservation as the physical quantity and is calculated based on the revised universal soil loss equation (RUSLE) $[38,39]$. The soil conservation value is the sum of maintaining the soil nutrient value and reducing the sedimentation value:

$$
\begin{gathered}
V_{s d}=\lambda \times\left(Q_{s r} / \rho\right) \times c \\
V_{d p d}=\sum_{i=1}^{n} Q_{s r} \times C_{i} \times R_{i} \times T_{i}
\end{gathered}
$$

where $V_{s d}$ is the value of reducing sedimentation $(\mathrm{CNY} / \mathrm{a}), V_{d p d}$ is the value of maintaining soil nutrients $(\mathrm{CNY} / \mathrm{a}), Q_{s r}$ is the amount of soil conservation (t/a), $c$ is the cost of the reservoir dredging project $\left(\mathrm{CNY} / \mathrm{m}^{3}\right)$ which can be obtained from the project cost of the water conservancy department, $\rho$ is the bulk density of the soil $\left(t / \mathrm{m}^{3}\right), \lambda$ is the sedimentation coefficient, $C_{i}$ is the pure content (\%) of the soil nutrients (such as nitrogen and phosphorus), $R_{i}$ is the ratio of nitrogen, phosphorus, potassium, and organic matter converted into their corresponding fertilizers (urea, superphosphate, potassium chloride, and carbon, respectively), and $T_{i}$ is the price (CNY) of the fertilizers, which can be determined according to the market price.

\subsubsection{Sand Fixing}

Using the amount of sand fixing as the physical quantity, which is calculated based on the revised wind erosion model (RWEQ) [40-42], the value was calculated using the restoration cost method, and the price parameter was the cost of the sand control project:

$$
V_{s f}=\frac{Q_{s f}}{\rho \cdot h} \times c
$$

where $V_{s f}$ is the value of sand fixing (CNY/a), $Q_{s f}$ is the amount of sand fixing ( $\left.\mathrm{t} / \mathrm{a}\right), \rho$ is the bulk density of the soil $\left(\mathrm{t} / \mathrm{m}^{3}\right), h$ is the thickness of sand-covered soil $(\mathrm{m})$, and $c$ is the cost of the sand control project $\left(\mathrm{CNY} / \mathrm{m}^{2}\right)$, which can be obtained from the environmental protection department.

\subsubsection{Flood Regulation}

The sum of the lake flood storage capacity, the flood regulation storage capacity of the reservoir, and the flood stagnant water capacity of the marshland are regarded as the physical quantity of flood regulation [43]. The shadow engineering method was used to obtain the value quantity, and the engineering cost and maintenance cost of the reservoir were used as the price parameters:

$$
\begin{gathered}
F M C=3.19 \times e^{4.924} \times A^{1.128}+0.35 C_{t}+1 \times S \times 10^{6} \\
F M V=F M C \times C_{w v}
\end{gathered}
$$

where FMC is the amount of flood regulation $\left(\mathrm{m}^{3} / \mathrm{a}\right), A$ is the area of the lake $\left(\mathrm{km}^{2}\right), C_{t}$ is the total capacity of the reservoir $\left(\mathrm{m}^{3} / \mathrm{a}\right), S$ is the area of marshland $\left(\mathrm{km}^{2}\right)$, and $C_{w v}$ is the engineering cost and maintenance cost of the reservoir $\left(\mathrm{CNY} / \mathrm{m}^{3}\right)$, which can be obtained from the project cost of the water conservancy department. 


\subsubsection{Carbon Fixation and Oxygen Release}

The amount of fixed carbon dioxide was selected as the physical amount of carbon fixation, and the calculation was based on the net primary productivity (NPP) [44]. The amount of oxygen released was converted based on the amount of carbon fixation, and the value of carbon fixation and oxygen release was calculated using the replacement cost method. The carbon trading price and the oxygen production price were selected as price parameters:

$$
\begin{aligned}
Q_{\mathrm{tco} 2} & =1.63 \times N P P \quad V_{C}=Q_{\mathrm{CO}_{2}} \times C_{C} \\
P_{o} & =Q_{\mathrm{tco} 2} \times 0.73 \quad V_{o}=P_{o} \times O P
\end{aligned}
$$

where $Q_{t c o 2}$ is the amount of fixed carbon dioxide $(\mathrm{t} C / \mathrm{a}), N P P$ is the net primary productivity $(\mathrm{t} C / \mathrm{a}), C_{C}$ is the carbon trading price $(\mathrm{CNY} / \mathrm{t})$ which can be determined according to the market price, $P_{o}$ is the amount of oxygen released $(t / a), O P$ is the oxygen production price $(\mathrm{CNY} / \mathrm{t})$ which can be determined according to the medical oxygen production price, and $V_{C}$ and $V_{o}$ are the values of carbon fixing and oxygen release, respectively (CNY/a).

\subsubsection{Climate Regulation}

The total energy consumed by vegetation transpiration and water evaporation was used as the physical quantity of climate regulation $[45,46]$. The replacement cost method was used for value calculation, and the price parameter was the living electricity price:

$$
\begin{gathered}
E_{p t}=\sum_{i}^{3} E P P_{i} \times S_{i} \times D \times 10^{6} /(3600 * r) \\
E_{w e}=E_{w} \times q \times 10^{3} /(3600)+E_{w} \times y \\
V_{t t}=\left(E_{p t}+E_{w e}\right) \times P_{e}
\end{gathered}
$$

where $E_{p t}$ and $E_{w e}$ are the energy consumed by vegetation transpiration and water evaporation, respectively $(\mathrm{kW} \cdot \mathrm{h} / \mathrm{a}), E P P_{i}$ is the energy consumed by vegetation transpiration per unit $\left(\mathrm{kJ} \cdot \mathrm{m}^{-2} \mathrm{~d}^{-1}\right), S_{i}$ is the area of the different ecosystems $\left(\mathrm{km}^{2}\right), D$ is the number of days when the daily maximum temperature is greater than $26^{\circ} \mathrm{C}, r$ is the energy efficiency ratio of the air conditioner, $E_{w}$ is the water evaporation $\left(\mathrm{m}^{3}\right), q$ is the latent heat of evaporation $(\mathrm{J} / \mathrm{g}), \mathrm{y}$ is the amount of electricity consumed by the humidifier to convert 1 ton of water into steam $(\mathrm{kW} \cdot \mathrm{h}), V_{t t}$ is the value of climate regulation $(\mathrm{CNY} / \mathrm{a})$, and $P_{e}$ is the electricity price $(\mathrm{CNY} / \mathrm{kW} \cdot \mathrm{h})$.

\subsubsection{Cultural Services}

Cultural services are the nonmaterial benefits that humans obtain from the ecosystem through spiritual experience, knowledge acquisition, leisure and entertainment, and aesthetic experience. The travel cost method was used to evaluate the aesthetic value of people experiencing the ecosystem and natural landscape through leisure and tourism activities and to obtain the nonmaterial value of knowledge acquisition and spiritual pleasure $[27,47,48]$ :

$$
\begin{gathered}
V_{r}=\sum_{j=1}^{J} N_{j} \times T C_{j} \\
T C_{j}=T_{j} \times W_{j}+C_{j} C_{j}=C_{t c, j}+C_{l f, j}+C_{e f, j}
\end{gathered}
$$

where $V_{r}$ is the cultural services value, $N_{j}$ is the total number of visitors traveling to the accounted area from place $j, T C_{j}$ is the average travel cost of tourists from place $j, T_{j}$ is the average time spent by tourists from place $j$ to the accounted area, $W_{j}$ is the local average salary of place $j$, and $C_{j}$ is the average direct travel cost spent by tourists, including the travel expenses $C_{t c, j}$, lodging expenses $C_{l f, j}$, and tickets cost $C_{e f, j}$.

In the evaluation of the above ecosystem service functions, the methods of physical quantity were selected and constructed based on the mechanism characteristics of each function, and each model was also successfully applied in corresponding research. The 
value quantities were calculated with reference to specific project materials and market prices. Compared with other studies of ecosystem service functions, the method of this study was more practical, and the acquisition of various parameters was more convenient, which avoided errors caused by conversion between different expressions.

\subsection{Data Processing}

The time scale of this study was from 2015 to 2018, and the data used included land use data, meteorological data, remote sensing data, topographical data, soil data, and statistics. The land use data, topographical data, and soil data were acquired from the Data Center for Resources and Environmental Sciences at the Chinese Academy of Sciences; the meteorological data were from the China Meteorological Date Service Center; the remote sensing data were mainly the Moderate Resolution Imaging Spectroradiometer (MODIS) product data from National Aeronautics and Space Administratio (NASA); and the statistical data were from national and local statistical yearbooks. Based on the land use data classification system, six ecosystems were identified: farmland, forest, grassland, wetland, urban, and desert ecosystems. Point data, such as meteorological data, were extended to the area by the interpolation method. All the spatial data were processed by GIS and remote sensing software with the resolution configured as $1 \mathrm{~km} \times 1 \mathrm{~km}$, and all statistical data were processed by SPSS and Excel.

\section{Results}

\subsection{Ecosystem Pattern}

Due to the relatively small changes in the area of the ecosystems between adjacent years, this study conducted a comparative analysis of only the ecosystem patterns in 2015 and 2018. As illustrated in Figure 2, there were large differences in the patterns of the ecosystems in the two basins. The grassland ecosystem in the Yellow River Basin had the largest area, accounting for more than $45 \%$, while the forest ecosystem area accounted for less than $12 \%$. However, the area of the forest ecosystem in the Yangtze River Basin was significantly higher than the other types, reaching $760,000 \mathrm{~km}^{2}$ in 2018 and accounting for approximately $39 \%$ of the area, and the areas of the farmland and grassland ecosystems were similar, accounting for approximately $25 \%$. A comparison between the two basins showed that, except for the grassland and desert ecosystems, the area of the other ecosystems in the Yangtze River Basin exceeded that of the Yellow River Basin, especially farmland and forest, whose areas were approximately twice and six times those in the Yellow River Basin, respectively. From 2015 to 2018, all ecosystem areas, except for the areas of farmland and desert, increased in the Yellow River Basin, with the grassland area increasing by $13,000 \mathrm{~km}^{2}$, urban area increasing by $7000 \mathrm{~km}^{2}$, and desert area decreasing by $17,000 \mathrm{~km}^{2}$. The Yangtze River Basin saw an increase in the urban and forest areas by $11,000 \mathrm{~km}^{2}$ and $8000 \mathrm{~km}^{2}$, respectively, and a decrease in the farmland and grassland areas by $7000 \mathrm{~km}^{2}$ and $9000 \mathrm{~km}^{2}$, respectively.

Spatially (Figure 3), the farmland in the Yellow River Basin is relatively concentrated, with the majority of farmland located in the Fen-wei Plain and along the banks of the Yellow River in the Henan and Shandong provinces. Farmland and grassland are interlaced in Shaanxi, Gansu, and part of Ningxia in the northwestern part of the Fen-wei Plain, whereas Inner Mongolia and parts of Qinghai are dominated by grassland. The forest is distributed in a more scattered pattern, mainly in the Qilian Mountains, along the Fen River Basin and in the western part of Henan province. The farmland of the Yangtze River Basin is mainly distributed in the Sichuan Basin, the central part of Hubei downstream of the Yangtze River, the border between Henan and Hubei, and the Jiangsu and Zhejiang provinces. The forest is present in the entire basin, especially in the middle and lower reaches. The grassland is mainly distributed in the northwestern part of Sichuan province and the southern part of Qinghai province. A comparison of the spatial distribution between the two basins showed that the distribution of farmland and forest is on a much wider scale in the Yangtze River Basin than that in the Yellow River Basin, whereas the distribution of grassland and desert 
is relatively wider in the Yellow River Basin than in the Yangtze River Basin. From 2015 to 2018, the scope of the urban ecosystem visibly expanded in the study area. The western portion of the Yellow River Basin experienced a massive conversion of desert to grassland, and parts of the grassland in the central and western portions of the Yangtze River Basin were converted to forest. Spatial changes were nonsignificant for the other ecosystems.

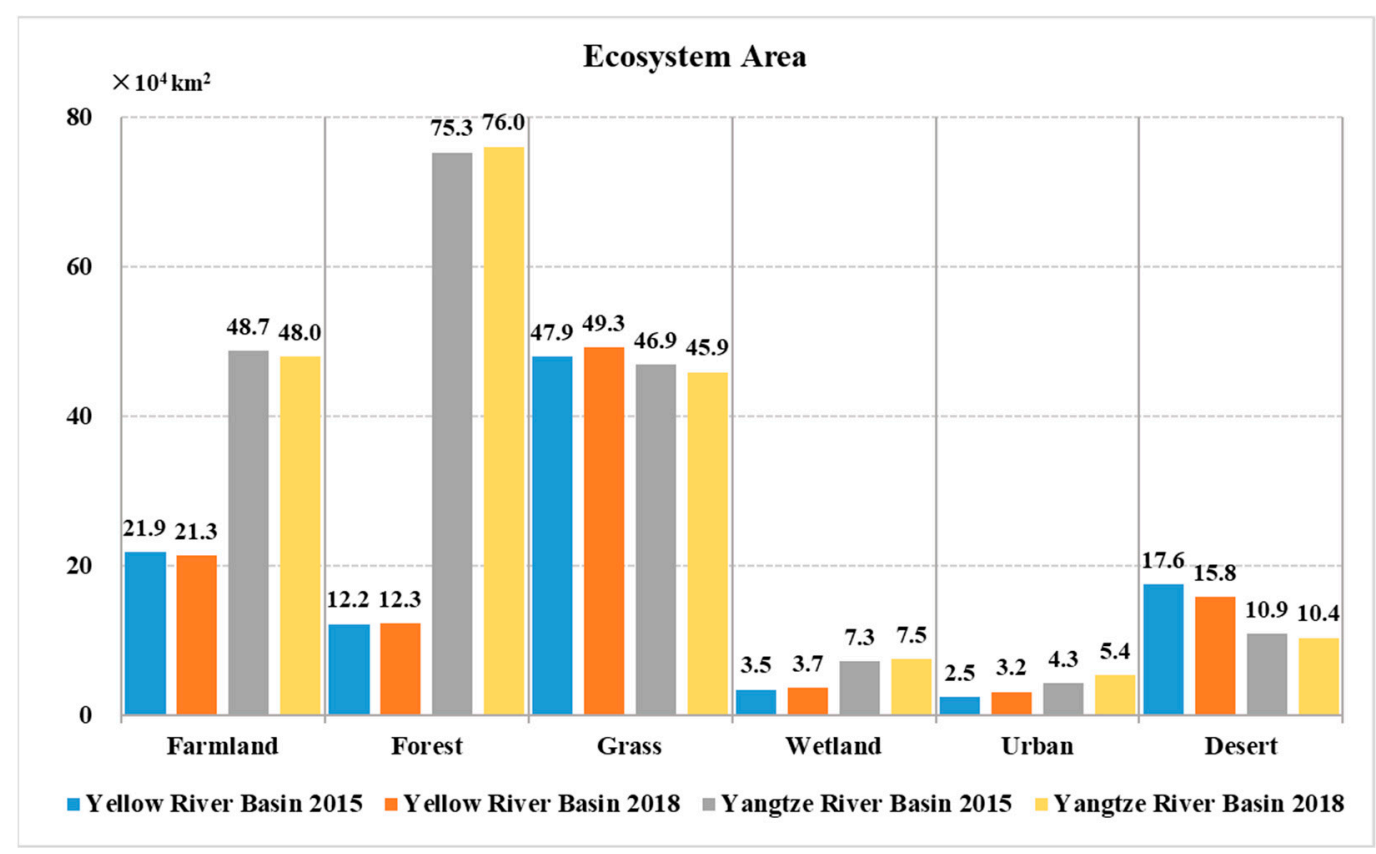

Figure 2. Areas of the different ecosystems in the two basins.
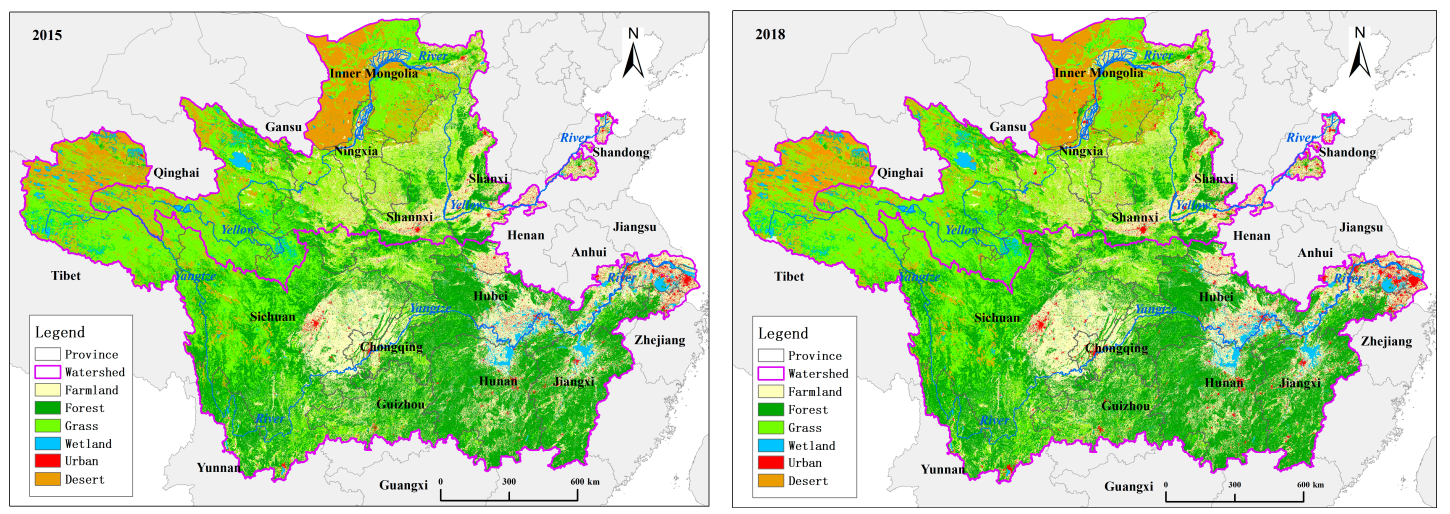

Figure 3. Spatial distributions of the different ecosystems in the two basins in 2015 and 2018.

\subsection{Ecosystem Service Value}

The values of different services were accounted for based on the ecosystem service value accounting models. As illustrated in Figure 4, the regulating service values in both basins were higher than the other two service values, exceeding the aggregate of the provisioning and cultural service values. The total ecosystem service values of the Yangtze River Basin from 2015 to 2018 (which were CNY 21.3 trillion, CNY 23.0 trillion, CNY 24.5 trillion, and CNY 25.7 trillion) were higher than those of the Yellow River Basin (which were CNY 6.6 trillion, CNY 7.2 trillion, CNY 7.4 trillion, and CNY 8.5 trillion), and the regulating service value was significantly higher than that of the Yellow River Basin, producing CNY 15.7 trillion and CNY 5.8 trillion, respectively, in 2018. The ecosystem service values increased between 2015 and 2018 for both basins, of which the increment and growth rate of the cultural service value outpaced the provisioning and regulating service 
values, reflecting the positive results in the transformation of ecological cultural services in both basins. The increment of the regulating service value in the Yangtze River Basin was higher than that in the Yellow River Basin, but the growth rate was outperformed by that in the Yellow River Basin. A comparison of the value per unit area showed that the total value of various services in the Yangtze River Basin was 13.3 million $\mathrm{CNY} / \mathrm{km}^{2}$ higher than that in the Yellow River Basin, which was 8.0 million CNY $/ \mathrm{km}^{2}$ in 2018. The regulating service value per unit area exceeded that of the provisioning and cultural services in both basins. Among the various services, only the value per unit area of sand fixing was higher in the Yellow River Basin than in the Yangtze River Basin.

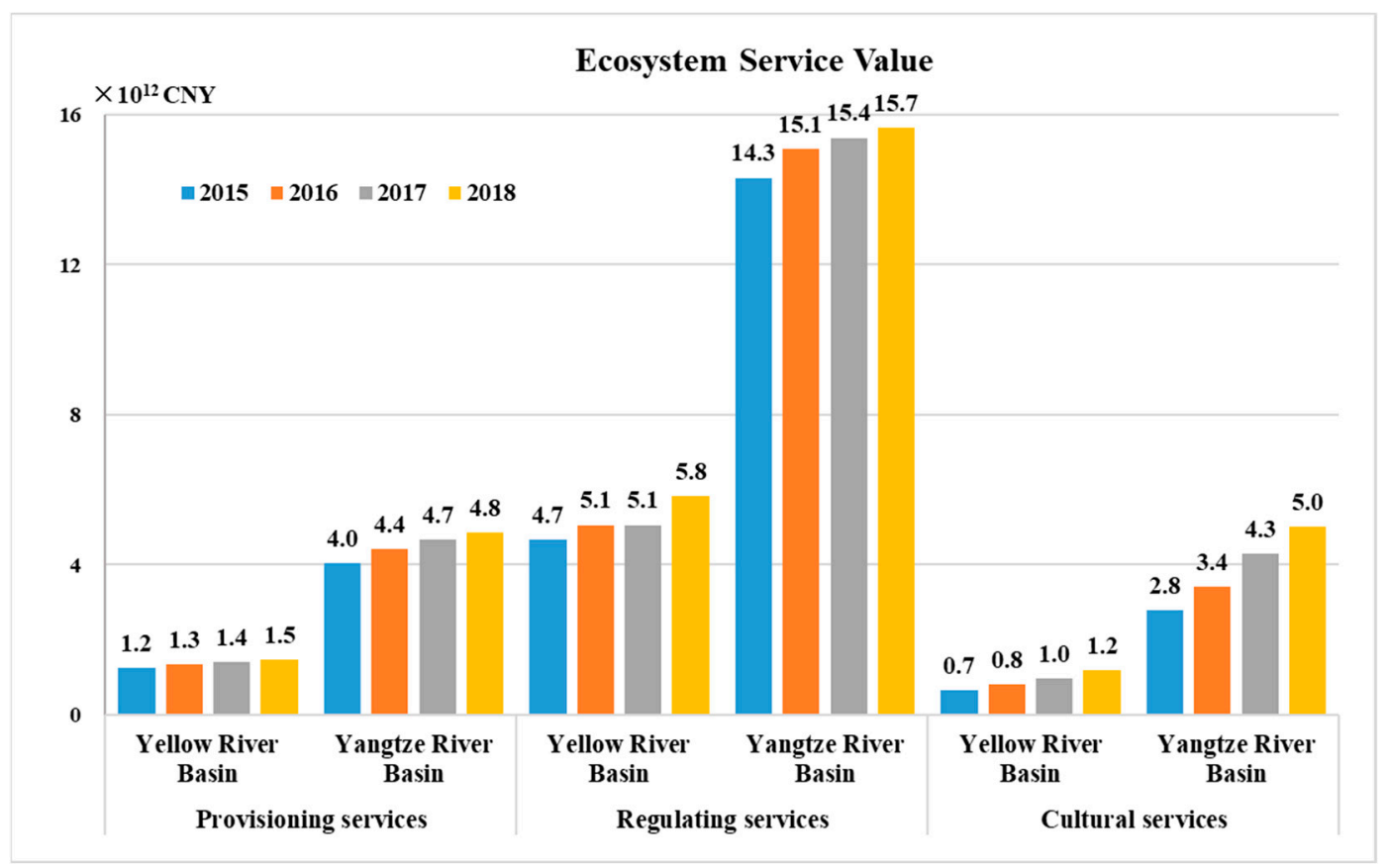

Figure 4. Ecosystem service values of the two basins from 2015 to 2018.

Spatially, the county-level administrative district was used as the statistical unit. Figure 5 shows that the ecosystem service value was generally higher in the west than in the east, with the central part having the lowest value. The counties of Yushu, which is located at the source of both the Yellow River and the Yangtze River, had the highest value. The total value was similar to the spatial distribution of the regulating service value. In the middle and upper streams of the Yangtze River, certain spatial complementarity manifested between the regulating service and the provisioning and culturing service values. For example, the Sichuan Basin is an important agricultural zone with a strong product supply capacity and is a heavily populated region with a more developed economy and eco-cultural tourism industry. Hence, it is endowed with a high cultural service value, but its regulating service capacity is lower than that of the surrounding regions due to the comparatively insignificant presence of ecosystems such as forests, grasslands, and wetlands.

Further statistical analysis of the regulating service value (Table 2) showed that the value of climate regulation had always been higher than other services, exceeding $70 \%$ and $60 \%$ of the regulation service value of the Yellow River Basin and the Yangtze River Basin, respectively, from 2015 to 2018. The statistics show that the highest share of climate regulation was provided by wetlands among all ecosystems, reaching CNY 3.7 trillion in the Yangtze River Basin in 2018. Water conservation and flood regulation accounted for over $20 \%$ and $30 \%$ of the total regulating service value, respectively. Compared with the Yangtze River Basin, the Yellow River Basin had lower values in all the regulating services, with the largest gap being in climate regulation, which reached CNY 5.7 trillion in 2017. 
The value for soil conservation and water conservation in the Yangtze River Basin was three to fourteen times that of the Yellow River Basin, whereas the value of sand fixing showed little difference.
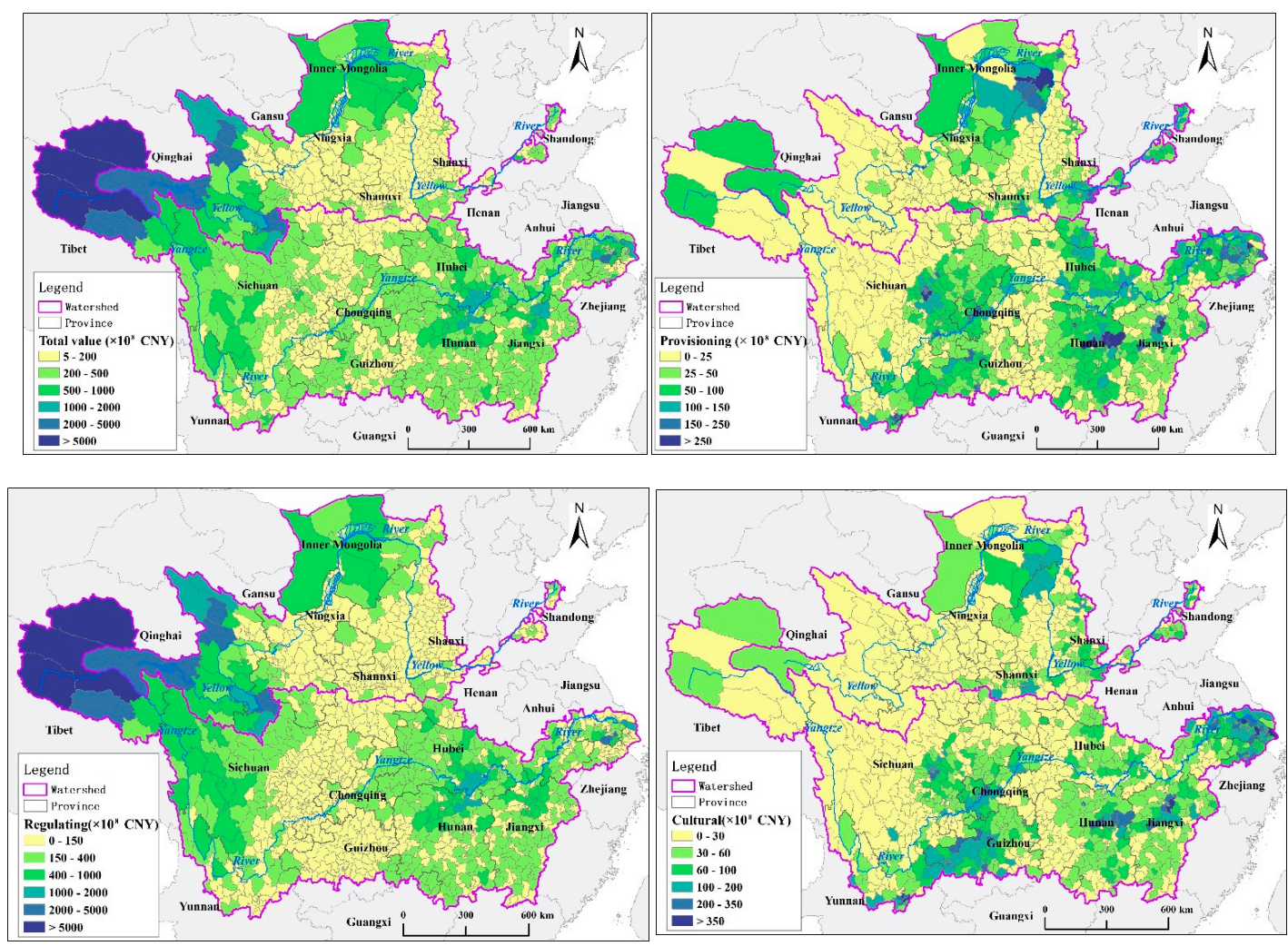

Figure 5. Spatial distributions of the ecosystem service values of the two basins.

Table 2. Values of the regulation services in the two basins from 2015 to $2018\left(\times 10^{8} \mathrm{CNY}\right)$.

\begin{tabular}{cccccc}
\hline Services & River Basin & $\mathbf{2 0 1 5}$ & $\mathbf{2 0 1 6}$ & $\mathbf{2 0 1 7}$ & $\mathbf{2 0 1 8}$ \\
\hline Carbon fixation and & Yellow River Basin & 2058.1 & 4003.5 & 1875.5 & 3123.4 \\
oxygen release & Yangtze River Basin & 9682.2 & $10,864.9$ & $10,487.2$ & $10,336.5$ \\
\hline \multirow{2}{*}{ Water conservation } & Yellow River Basin & 1993.6 & 2979.7 & 2854.9 & 3768.1 \\
& Yangtze River Basin & $18,194.4$ & $20,706.8$ & $18,079.1$ & $19,090.8$ \\
\hline \multirow{2}{*}{ Flood regulation } & Yellow River Basin & 3933.4 & 4040.7 & 4124.7 & 4270.3 \\
and storage & Yangtze River Basin & $11,727.3$ & $12,681.1$ & $12,992.0$ & $13,340.8$ \\
\hline \multirow{2}{*}{ Climate regulation } & Yellow River Basin & $37,405.0$ & $37,891.7$ & $40,333.6$ & $39,953.9$ \\
& Yangtze River Basin & $88,570.1$ & $90,258.4$ & $97,534.3$ & $97,086.6$ \\
\hline \multirow{2}{*}{ Soil conservation } & Yellow River Basin & 1022.6 & 1169.1 & 1031.8 & 6717.9 \\
& Yangtze River Basin & $14,532.3$ & $15,816.7$ & $14,341.6$ & $16,250.0$ \\
\hline \multirow{2}{*}{ Sand fixing } & Yellow River Basin & 352.1 & 478.1 & 335.7 & 439.1 \\
& Yangtze River Basin & 475.8 & 440.5 & 412.9 & 464.3 \\
\hline
\end{tabular}

Figure 6 illustrates that the value of climate regulation was between 0.8 and 1.0 million $\mathrm{CNY} / \mathrm{km}^{2}$ in most regions in the Yangtze River Basin except for wetlands, while the figure was below 0.5 million CNY $/ \mathrm{km}^{2}$ in most regions in the Yellow River Basin except for the Fen-wei Plain. The value of carbon fixation and oxygen release had similar spatial distribution characteristics with climate regulation. On the other hand, the spatial distribution of the water conservation value showed significant variations, as the value was higher in the middle and lower reaches to the south of the Yangtze River, followed by the mountainous 
zones on the western rim of the Sichuan Basin, while the value was insignificant in other regions. The overall water conservation value of the Yellow River Basin was lower than that of the Yangtze River Basin, yet the value was higher in the northern and western parts of the basin, with larger areas of grassland than in the other parts. The soil conservation value was higher in the central part of the study area, especially in the western and northern parts of the Sichuan Basin, Loess Plateau, and central and southern parts of the Gansu province.
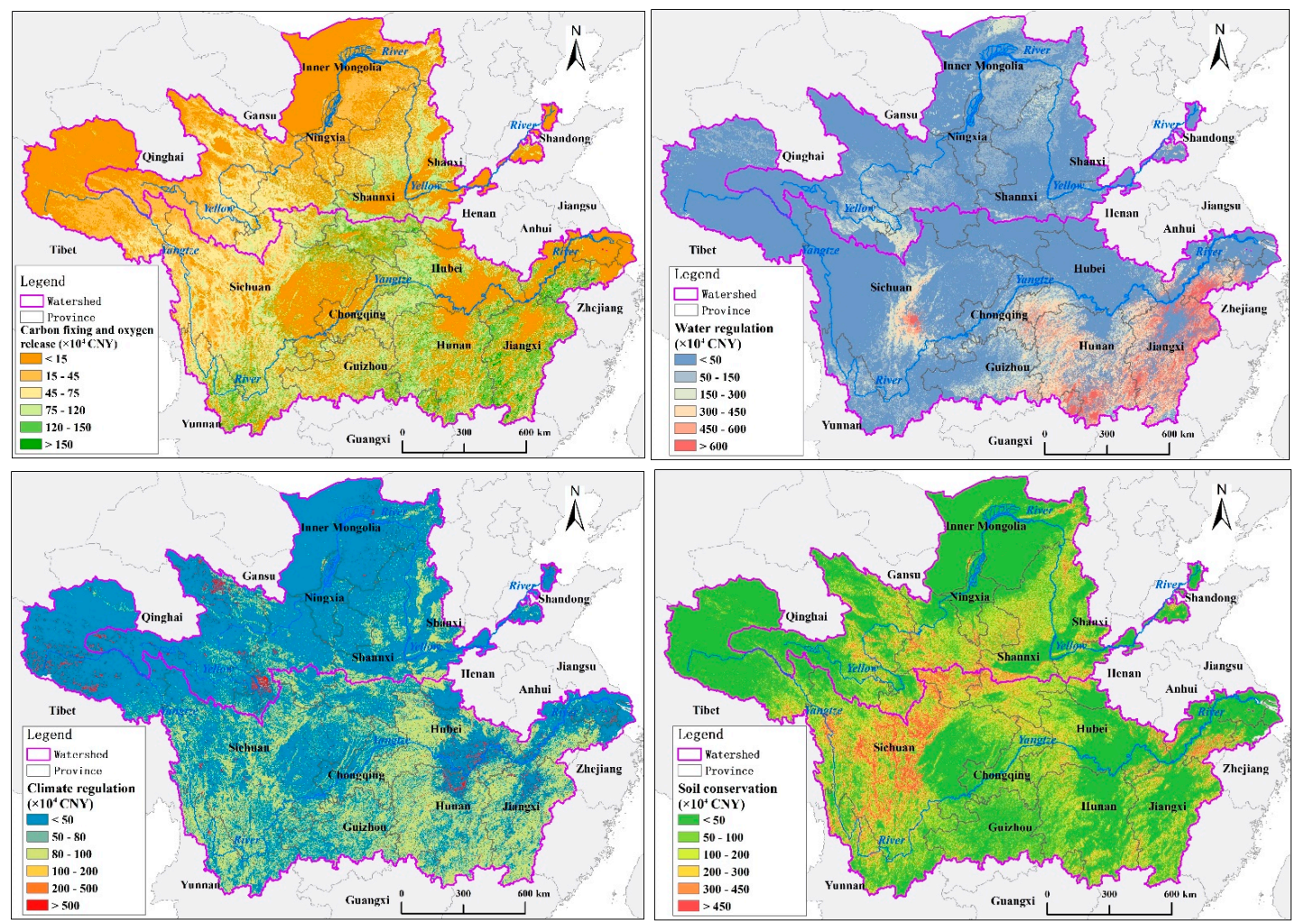

Figure 6. Spatial distributions of values of some services in the two basins in 2018.

\section{Discussion}

\subsection{Relationship between Ecosystem Pattern and Ecosystem Service Value}

Based on the results of the ecological patterns and their changes in the two basins, the size and scope of the farmlands surrounding urban regions are shrinking as the urbanization process continues in the basins. However, the implementation of numerous eco-environmental protection regulations and policies in recent years has effectively mitigated the adverse impact on the natural ecological system. Between 2015 and 2018, forest, grassland, and wetland ecosystems in the two basins remained stable in terms of area, and massive deserts in the source area of the rivers were converted to grassland. All these changes lead to the conclusion that ecological improvement and resilience are gradually taking place in both basins.

Improvement in the eco-environment has laid the foundation for the ecosystem service value to increase, with the regulating service generating higher value than the provisioning and cultural services. The wetland ecosystem generated the highest value per unit area in the climate regulation and flood regulation services, which resulted in the higher total value in the source area of the two rivers and in the counties with large areas of wetlands. The carbon fixation and oxygen release services were evaluated based on the ecosystem's NPP. As forests feature a higher NPP than other ecosystems, the Yangtze River Basin with larger forested areas had a higher total NPP. The accounting results showed that the NPPs per unit area in the Yellow River Basin and the Yangtze River Basin were $294.6 \mathrm{t} / \mathrm{km}^{2}$ and $517.4 \mathrm{t} / \mathrm{km}^{2}$, respectively, and areas of higher values of carbon fixation and oxygen 
release largely overlapped with forested areas. Meteorological factors also play a key role in creating differences in ecosystem service value. For instance, assessments of water conservation, climate regulation, soil conservation, and sand fixing values are based on precipitation, evaporation, temperature, and wind speed, among other factors. In addition, the improvement in the background conditions of ecosystems will lead to an abundance of ecological product harvesting, which attracts popularity as a tourist destination, hence showing higher value in provisioning and cultural services.

\subsection{Analysis of Economic Development and Ecosystem Service Value}

Regional economic development and the surrounding eco-environment are mutually influential. The following analysis adopted the GDP and gross ecosystem product (GEP) [4] as quantitative indicators to represent economic development and ecological environment quality, respectively. Figure 7 shows an increase in GDP and GEP in both river basins from 2015 to 2018, indicating the improvement in eco-environment quality while maintaining economic growth. The positive effects of eco-environmental protection policies and measures in recent years have shaped a basically healthy trend of synergetic development between the economy and environment in China. The ratio of GEP to GDP, named the GGI, is used to measure the complementarity between regional eco-environmental protection and economic development. Figure 7 shows that the GGI in the Yellow River Basin was above 1 with the curve deviating from 1, indicating that the degree and rate of ecological improvement decoupled from economic growth and that the economic potential of the eco-environment had not been fully tapped. The Yangtze River Basin, on the other hand, features a more developed and faster growing economy, with a GDP higher than the ecosystem service value and a GGI below 1, causing concern over the potential for ecological safety to be threatened by economic development.
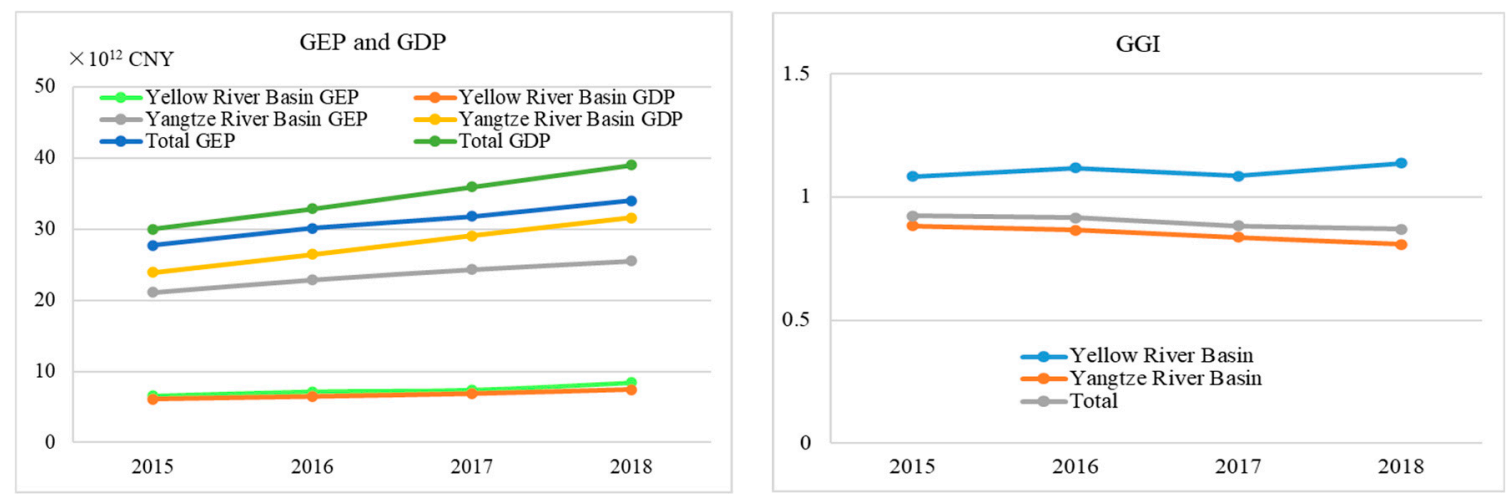

Figure 7. Relationship between gross ecosystem product (GEP) and gross national economic product (GDP) in the two basins from 2015 to 2018 .

Figure 8 illustrates the spatial distribution of GDP and GGI in the two basins in 2018. Spatially, the Yangtze River Basin contained more counties with higher GDPs than the Yellow River Basin. Fifty-one percent of the counties had their own GGIs above 1, and 58 of them had a GGI above 10, most of which were in the west part of Sichuan and Qinghai. These areas should explore the value methods of ecological products in the future to achieve synergy between ecological conservation and economic growth. Regions where the GDP exceeded the ecosystem service value (i.e., a GGI below 1) were distributed around the Yangtze River Delta, Changsha-Zhuzhou-Xiangtan, Sichuan, Chongqing, Fen-wei Plain, and downstream of the Yellow River. 

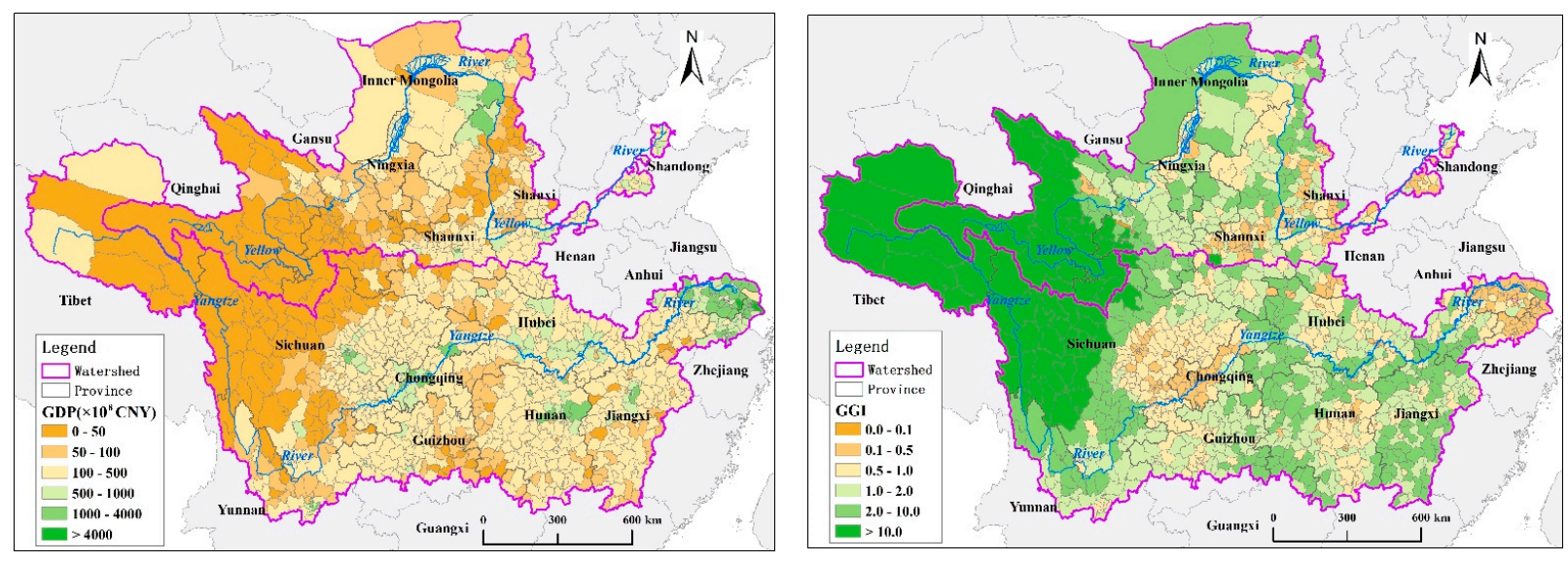

Figure 8. Spatial distributions of GDP and the GEP to GDP ratio (GGI) in the two basins in 2018.

This study selected the research on China's ecosystem service function assessment in 2015 [36] and the research on the supply and demand pattern of the ecosystem service functions in the Yangtze River Economic Zone [49] to compare. In terms of the value of ecosystem service functions per unit area, there was a similar trend in this study with Ma's research results, while in terms of spatial distribution patterns, the similarities between this study and Zhai's research results were mainly manifested in the Yangtze River Basin, where the volume of regulation services in the Sichuan Basin and downstream areas was relatively small.

Based on the above research results and analysis, the ecosystem pattern and changes had a direct impact on the ecosystem service value of the two basins and had reference value for the formulation and implementation of regional ecological environmental protection policies. The combined analysis of the ecosystem service value and the level of regional economic development can provide data support for the ecological protection and high-quality development of the two basins. For example, the formulation of ecological compensation policies for the upper, middle, and lower reaches of a single basin can be based on the value of ecosystem services and the comparison of different regional economic development levels, possibly leading to the design of ecological compensation standards and methods from the perspective of mobility. Moreover, based on the ratio and trend in the curve of the relationship between the GEP and GDP, decision-makers can make a reasonable plan for the future emphasizing ecological protection and economic development.

In addition, the evaluation method system proposed in this article was also scientifically reasonable, and the data used was easier to obtain, which provides scientific support for similar evaluation studies in other regions.

\section{Conclusions and Prospects}

This study accounted for the ecosystem service values of the Yellow River Basin and the Yangtze River Basin from 2015 to 2018 based on land use data, meteorological data, and soil data, as well as by adopting different ecological models. The evaluation results and their analysis led to the following conclusions.

Significant differences exist in the ecosystem patterns between the two basins. The Yangtze River Basin has better natural ecological endowment, higher fractional vegetation cover, and higher NPP, with forest ecosystems as the main component, while the Yellow River Basin, dominated by grassland ecosystems, has poorer vegetation, climatic, and soil conditions than the Yangtze River Basin. From 2015 to 2018, there were increased areas of forest, grassland, and wetland ecosystems and a reduced size and scope of desert ecosystems. Both river basins show ecological resilience, but the farmland ecosystem still faces a severe threat from urbanization.

In terms of spatial distribution, the ecosystem service value of the study area was highest in the west, followed by the east and the lowest being in the central part, and all 
ecosystem service values of the Yangtze River Basin were higher than those of the Yellow River Basin. With improvements in the eco-environment, the ecosystem service value grew from 2015 to 2018. The regulating service value was higher than the provisioning and cultural service values in the two basins. Spatial complementarity was noted in the three services due to the impact of ecosystem patterns, meteorology, and other factors. Climate regulation provided the highest value, followed by water conservation and flood regulation. Cultural services mainly refer to the cultural enjoyment and welfare brought to people by the natural or seminatural landscape, so it is also a strong indication of the quality of the entire ecosystem and the environment. This study only considered tourist travel expenses as cultural services. However, due to the failure to construct a reasonable and effective method, the benefits related to education and scientific research were not calculated. This is also a shortcoming of this research.

Both the eco-environment and socioeconomic development improved from 2015 to 2018 , with a gradual decline in GDP from the eastern to the western region, showing a spatial mismatch with the characteristics of the GEP. The accounted ecosystem service value outweighed the economic volume in most counties of the two basins, except for those in the Yangtze River Delta, Chengdu-Chongqing region, Changsha-Wuhan metropolitan area, and the area downstream of the Yellow River, where economic development surpassed the ecosystem service value. The ecological resilience of the Yellow River Basin outpaced far more than its economic development, but the Yangtze River Basin showed the opposite pattern, indicating that the former should draw on experiences from the latter in policy arrangements to tap the ecological advantages in its transformation.

In future research, we should focus on the application of accounting results and policy formulation and focus on the development of ecological compensation and ecological investment, as well as financing policy design based on the value of ecosystem services. Based on the accounting results, eco-compensation standards between upstream and downstream areas should be designed, horizontal ecological compensation based on water flow regulation and other services should be placed into practice, and an eco-compensation mechanism for water supply based on flow quantity and water quality urgently need to be established. The special transfer payment for eco-environmental protection should be encouraged to prioritize the impoverished regions with important ecological functions and abundant ecological resources within the basin, aiming at determining the criteria for fiscal transfer payments and horizontal ecological compensation based on the ecosystem service value. In addition, considering the comparison between the GEPs and GDPs in the two basins, it is recommended to apply the successful experience of ecological financing and ecological compensation practiced in the Yangtze River Basin to the Yellow River Basin to promote the synergetic development of the Yellow River. Taking the three Rivers Source Region, Qilian Mountain, and the upstream water conservation zone of the Yellow River in the south part of Gansu province as key areas, an ecological conservation and restoration fund should be proposed, and more ecological compensation should be made available for the area, with consideration toward water flow and water quality. Considering the variation in the natural ecological background and economic development levels of the upper, middle, and downstream areas of the Yellow River, natural ecological asset and eco-product trading should be implemented by innovating ecological financing policies.

Author Contributions: All authors contributed to all parts of the paper. The first author has the most important role in the conception, writing, modification, and data processing of the article. All authors have read and agreed to the published version of the manuscript.

Funding: This research was funded by the National Key Research and Development Program of China (2018YFC0214103-04), construction of environmental assets accounting system of the Chinese Academy of Environmental Planning (144018000000200047), and the National Natural Science Foundation of China (Grant 41801354).

Institutional Review Board Statement: Not applicable.

Informed Consent Statement: Not applicable. 
Data Availability Statement: The data that support the findings of this study are available on request from the corresponding author. The data set are not publicly available due to the privacy of the respondents.

Conflicts of Interest: The authors declare no conflict of interest.

\section{References}

1. Baniya, B.; Tang, Q.; Pokhrel, Y.; Xu, X. Vegetation dynamics and ecosystem service values changes at national and provincial scales in Nepal from 2000 to 2017. Environ. Dev. 2019, 32, 100464. [CrossRef]

2. Sun, Y.; Ren, Z.; Hao, M.; Duan, Y. Spatial and temporal changes in the synergy and trade-off between ecosystem services, and its influencing factors in Yanan, Loess Plateau. Acta Ecol. Sin. 2019, 39, 3443-3454.

3. Su, K.; Wei, D.-Z.; Lin, W.-X. Evaluation of ecosystem services value and its implications for policy making in China-A case study of Fujian province. Ecol. Indic. 2020, 108, 105752. [CrossRef]

4. $\quad$ Ouyang, Z.; Song, C.; Zheng, H.; Polasky, S.; Xiao, Y.; Bateman, I.J.; Liu, J.; Ruckelshaus, M.; Shi, F.; Xiao, Y.; et al. Using gross ecosystem product (GEP) to value nature in decision making. Proc. Natl. Acad. Sci. USA 2020, 117, 14593-14601. [CrossRef] [PubMed]

5. Costanza, R. The value of the world's ecosystem services and natural capital. Ecol. Econ. 1998, 25, 3-15. [CrossRef]

6. Costanza, R.; Arge, R.; de Groot, R.; Farber, S.; Grasso, M.; Hannon, B.; Limburg, K.; Naeem, S.; Oneill, R.V.; Paruelo, J.; et al. The value of the world's ecosystem services and natural capital. Nature 1997, 387, 253-260. [CrossRef]

7. Daily, G.C.; Soderqvist, T.; Aniyar, S.; Arrow, K.; Dasgupta, P.; Ehrlich, P.R.; Folke, C.; Jansson, A.; Jansson, B.O.; Kautsky, N.; et al. Ecology-The value of nature and the nature of value. Science 2000, 289, 395-396. [CrossRef] [PubMed]

8. Costanza, R. Valuing natural capital and ecosystem services toward the goals of efficiency, fairness, and sustainability. Ecosyst. Serv. 2020, 43, 101096. [CrossRef]

9. Badamfirooz, J.; Mousazadeh, R. Quantitative assessment of land use/land cover changes on the value of ecosystem services in the coastal landscape of Anzali International Wetland. Environ. Monit. Assess. 2019, 191, 1-13. [CrossRef]

10. Kalfas, D.G.; Zagkas, D.T.; Dragozi, E.I.; Zagkas, T.D. Estimating value of the ecosystem services in the urban and peri-urban green of a town Florina-Greece, using the CVM. Int. J. Sustain. Dev. World Ecol. 2020, 27, 310-321. [CrossRef]

11. Solomon, N.; Segnon, A.C.; Birhane, E. Ecosystem Service Values Changes in Response to Land-Use/Land-Cover Dynamics in Dry Afromontane Forest in Northern Ethiopia. Int. J. Environ. Res. Public Health 2019, 16, 4653. [CrossRef]

12. Xie, Q.; Yue, Y.; Sun, Q.; Chen, S.; Lee, S.-B.; Kim, S.W. Assessment of Ecosystem Service Values of Urban Parks in Improving Air Quality: A Case Study of Wuhan, China. Sustainability 2019, 11, 6519. [CrossRef]

13. Zhao, X.; He, Y.; Yu, C.; Xu, D.; Zou, W. Assessment of Ecosystem Services Value in a National Park Pilot. Sustainability 2019, 11, 6609. [CrossRef]

14. Gao, Y.; Zhang, L.; Li, K.; Li, F.; Li, D.; Yu, H.; Jia, Z. An Indicator System for Estimating Ecosystem Values. Res. Environ. Sci. 2019, 32, 58-65.

15. Pedersen Zari, M. Ecosystem services analysis for the design of regenerative built environments. Build. Res. Inf. 2012, 40, 54-64. [CrossRef]

16. Russo, A.; Cirella, G.T. Urban Ecosystem Services: New Findings for Landscape Architects, Urban Planners, and Policymakers. Land 2021, 10, 88. [CrossRef]

17. Zhou, P.; Zhou, T.; Peng, S. Measurement modalities and methodologies of ecosystem services valuation. Acta Ecol. Sin. 2019, 39, 5379-5388.

18. Pedersen Zari, M.; Hecht, K. Biomimicry for Regenerative Built Environments: Mapping Design Strategies for Producing Ecosystem Services. Biomimetics 2020, 5, 18. [CrossRef]

19. Marques, B.; McIntosh, J.; Hatton, W.; Shanahan, D. Bicultural landscapes and ecological restoration in the compact city: The case of Zealandia as a sustainable ecosanctuary. J. Landsc. Archit. 2019, 14, 44-53. [CrossRef]

20. Costanzaa, R.; de Groot, R.; Sutton, P.; van der Ploeg, S.; Anderson, S.J.; Kubiszewski, I.; Farber, S.; Turner, R.K. Changes in the global value of ecosystem services. Glob. Environ. Chang. 2014, 26, 152-158. [CrossRef]

21. Huai'en, L.; Meimei, X.; Yu, Z. Study on River Ecological Base Flow Value and Its Changes during the Year Based on Emergy Method. Ecol. Econ. 2017, 33, 160-164.

22. Xie, G.; Lu, C.; Leng, Y.; Zheng, D.; Li, S. Ecological assests valuation of the Tibetan Plateau. J. Nat. Resour. 2003, 18, 189-196.

23. Li, G.; Fang, C. Global mapping and estimation of ecosystem services values and gross domestic product: A spatially explicit integration of national 'green GDP' accounting. Ecol. Indic. 2014, 46, 293-314. [CrossRef]

24. Talukdar, S.; Singha, P.; Shahfahad; Mahato, S.; Praveen, B.; Rahman, A. Dynamics of ecosystem services (ESs) in response to land use land cover (LU/LC) changes in the lower Gangetic plain of India. Ecol. Indic. 2020, 112, 106121. [CrossRef]

25. Wang, X.; Peng, S.; Ling, H.; Xu, H.; Ma, T. Do Ecosystem Service Value Increase and Environmental Quality Improve due to Large-Scale Ecological Water Conveyance in an Arid Region of China? Sustainability 2019, 11, 6586. [CrossRef]

26. Xie, G.; Zhang, C.; Zhang, L.; Chen, W.; Li, S. Improvement of the Evaluation Method for Ecosystem Service Value Based on Per Unit Area. J. Nat. Resour. 2015, 30, 1243-1254.

27. Li, L.; Wang, X.; Luo, L.; Ji, X.; Zhao, Y.; Zhao, Y.; Nabil, B. A systematic review on the methods of ecosystem services value assessment. Chin. J. Ecol. 2018, 37, 1233-1245. 
28. Wang, Y.; Pan, J. Building ecological security patterns based on ecosystem services value reconstruction in an arid inland basin: A case study in Ganzhou District, NW China. J. Clean. Prod. 2019, 241, 118337. [CrossRef]

29. Cui, P.; Zhao, Y.; Xia, S.; Yan, J. Level Measures and Temporal and Spatial Coupling Analysis of Ecological Environment and High Quality Development in the Yellow River Basin. Econ. Geogr. 2020, 40, 49-57.

30. Ding, Z.; Xiao, N.; Gao, X.; Zheng, H.; Xiao, Y.; Kong, L.; Ouyang, Z.; Li, R. Changes of Ecosystem Quality and Services between 2000 and 2015 in Yangtze River Basin. Res. Environ. Sci. 2020, 33, 1308-1314.

31. Yuan, W. Ecological Compensation and protection of the Yellow River Basin. Environ. Prot. 2011, 27-29.

32. Zeng, X.; Liu, J.; Niu, M. Analysis on Environmental Efficiency of the Yellow River Basin under High Quality Development. Ecol. Econ. 2020, 36, 1-13.

33. Li, X.; Wen, Y.; Li, Y.; Yang, H. High-Quality Development of the Yellow River Basin from a Perspective of Economic Geography: Man-Land and Spatial Coordination. Ecol. Econ. 2020, 40, 1-10.

34. Ma, H.; Xu, X. High-Quality Development Assessment and Spatial Heterogeneity of Urban Agglomeration in the Yellow River Basin. Ecol. Econ. 2020, 40, 11-18.

35. Wang, S.; Zhao, X. On the deliberative-shared governance mode of ecological environment in the Yangtze River Basin. China Popul. Resour. Environ. 2019, 29, 31-39.

36. Ma, G.; Yu, F.; Wang, J.; Zhou, X.; Yuan, J.; Mou, X.; Zhou, Y.; Yang, W.; Peng, F. Measuring gross ecosystem product (GEP) of 2015 for terrestrial ecosystems in China. China Environ. Sci. 2017, 37, 1474-1482.

37. Zhang, B.; Xie, G.; Xue, K.; Wang, J.; Xiao, Y.; Zhang, C. Evaluation of rainwater runoff storage by urban green spaces in Beijing. Acta Ecol. Sin. 2011, 31, 3839-3845.

38. Liu, Y.; Liu, X.; Zhang, B.; Li, M. Evaluation of Soil and Water Conservation Function of Artificial Shrub-Grassland Ecosystem in Hilly Region of the Loess Plateau. J. Soil Water Conserv. 2020, 34, 84-90, 97.

39. Qiu, C.; Mao, Q.; Dong, Q. Estimation of Soil Conservation Ecological Service Function Value and Its Temporal and Spatial Changes in the Loess Plateau. J. Anhui Agric. Sci. 2018, 46, 104-107, 135.

40. Wenfeng, C.; Wenke, B.; Zhengjia, L.; Xiaohong, D.; Wenhui, K. Wind erosion in Inner Mongolia Plateau using the revised wind erosion equation. Ecol. Environ. Sci. 2018, 27, 1024-1033.

41. Guoli, G.; Jiyuan, L.; Quanqin, S. Wind erosion in Xilingol League, Inner Mongolia since the 1990s using the Revised Wind Erosion Equation. Progeress Geogr. 2014, 33, 825-834.

42. Ling, J.; Yi, X.; Zhiyun, O.; Weihua, X.; Hua, Z. Estimate of the Wind Erosion Modules in Qinghai Province Based on RWEQ Model. Res. Soil Water Conserv. 2015, 22, 21-25, 32.

43. Rao, E.; Xiao, Y.; Ouyang, Z. Assessment of Flood Regulation Service of Lakes and Reservoirs in China. J. Nat. Resour. 2014, 29, 1356-1365.

44. Zheng, H.; Wang, L.J.; Peng, W.J.; Zhang, C.P.; Li, C.; Robinson, B.E.; Wu, X.C.; Kong, L.Q.; Li, R.N.; Xiao, Y.; et al. Realizing the values of natural capital for inclusive, sustainable development: Informing China's new ecological development strategy. Proc. Natl. Acad. Sci. USA 2019, 116, 8623-8628. [CrossRef] [PubMed]

45. Yang, S. A Study on the Effect of Decreasing Temperature and Increasing Humidity of Urban Afforestation Trees. Geogr. Res. 1994, 13, 74-80.

46. Zhang, B.; Gao, J.; Xie, G.; Wang, Y. Preliminary evaluation of air temperature reduction of urban green spaces in Beijing. Acta Ecol. Sin. 2012, 32, 7698-7705. [CrossRef]

47. Yu, S.; Shang, J.; Guo, H. The Economical Assessment of Ecosystem Services and Natural Capital. China Popul. Resour. Environ. 2004, 14, 44-46.

48. Dong, L. Review on Evaluation of Ecosystem Services Value. J. Beijing For. Univ. 2011, 10, 59-64.

49. Tianlin, Z.; Jing, W.; Zhifeng, J.; Yuan, Q. Change and correlation analysis of the supply-demand pattern of ecosystem services in the Yangtze River Economic Belt. Acta Ecol. Sin. 2019, 39, 5414-5424. 